\title{
MORPHOLOGICAL CHANGES OF THE ENDOMETRIUM IN HYPERPLASTIC PROCESS IN WOMEN OF REPRODUCTIVE AGE
}

DOI: 10.36740/WLek202103102

\author{
Tetiana V. Vereshchahina', Alla V. Boychuk', Yuliia B. Yakymchuk', Iryna M. Nikitina², Tetiana V. Datsko' \\ II. YA. HORBACHEVSKY TERNIOPIL NATIONAL MEDICAL UNIVERSITY, TERNOPIL, UKRAINE \\ 2SUMY STATE UNIVERSITY, SUMY, UKRAINE
}

\begin{abstract}
The aim: To conduct a morphological study of endometrial tissue to identify changes characteristic of viral lesions to develop improved antirelapse treatment of HPE in women of reproductive age.

Materials and methods: We surveyed 90 patients of the gynecological department who sought medical for hyperplastic processes of the endometrium in reproductive age. All women underwent hysteroscopy, the resulting material was subjected to morphological examination.

Results: It became known that the virus is involved in the pathogenesis of endometrial hyperplasia. It is likely that it exists in epitheliocytes not only as a "passenger", but also as an etiological factor. It became known that it was in complex hyperplasia with atypia that the percentage reached the highest level, which is a precancerous condition. Conclusions: Typical morphological change of the endometrium - multinucleation, multinuclearity and koilocytotic atypia in women of childbearing age with HPE - was revealed. The presence of infectious pathogens in the endometrium of patients with HPE can be regarded as one of the possible triggers for the development of hyperplastic processes.
\end{abstract}

KEY WORDS: hyperplastic processes of the endometrium; morphological changes of the endometrium; infectious agents

Wiad Lek. 2021;74(3 p.l):388-394

\section{INTRODUCTION}

Endometrial hyperplasia (EH) is the most common pathology of the uterine body in women of childbearing age, manifested by uneven non-invasive proliferation of endometrial glands with a violation of the glandular-stromal ratio in comparison with the proliferative type endometrium, with its functional and morphological changes. According to the scientific literature, $\mathrm{EH}$ is $15-40 \%$ of all gynecological pathology [1-3].

Scientific publications on this issue allowed us to analyze some etiopathogenetic, ways in the formation of hyperplastic changes in endometrial tissue, in particular to assess the role of infectious factors as a provoking and etiological factor in the occurrence of HPE [4-9].

A number of authors consider HPE as a clinical and morphological syndrome caused by damage to the endometrium by pathogen infections, with numerous secondary morphological and functional changes that disrupt cyclic biotransformation and susceptibility of the mucous membrane of the uterus [10-14]. Other scientists also note the role of the infectious factor in the occurrence of $\mathrm{EH}$ despite the lack of growth of the microflora in crops from the uterine cavity [15-19].

A recent study showed that the herpes virus and HVI in endometrial biopsy persist in $40.7 \%$ of women with chronic endometritis, microbial viral associations - in 35\% [20-23]. Some researchers have demonstrated the possible involvement of viral infection in the occurrence of atypia in HPE, in particular, reports of the presence of HPV in adenocarcinomas of endometrial tissue have been published $[16,24-27]$. However, diseases caused by HVI in the female genitals are usually associated with specific areas: the vulva, vagina, cervix and uterine body, where there is a specific epithelium-stratified squamous cell, leading to epithelial cell proliferation and often to atypia. In contrast to the molecular diversity of microbes, morphological manifestations of tissue reactions to microorganisms, as well as morphogenetic mechanisms of these changes are often pathognomonic for a particular microorganism, which should certainly be considered in histological diagnosis. The question arises whether morphological changes can be detected in any tissues, indicating, for example, HPI [10, 25, 28].

The study of research results, in our opinion, indicates the feasibility of further study of the role of viral infection as an etiopathogenetic factor in the occurrence of HPE, as well as the study of the spectrum of viral infection and the role of individual viruses in the occurrence and recurrence of HPE. The study of these features will expand the possibilities of predicting the course and prospects of preventive treatment of relapses in HPE.

\section{THE AIM}

To conduct a morphological study of endometrial tissue to identify changes characteristic of viral lesions to develop improved antirelapse treatment of HPE in women of reproductive age. 


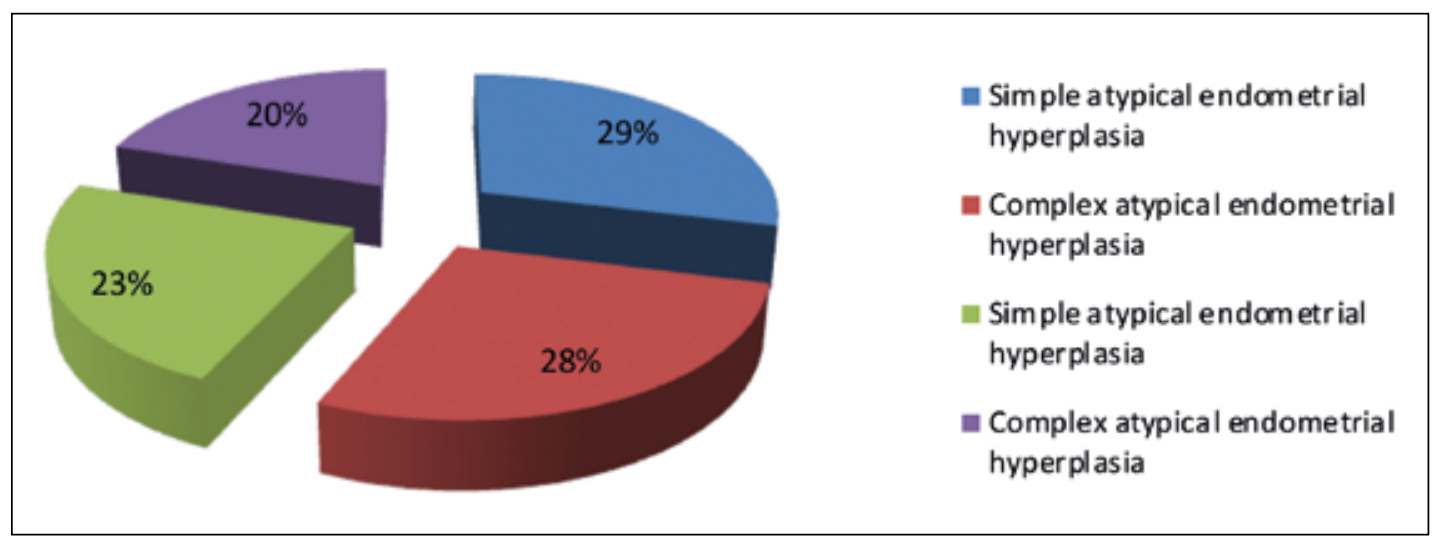

Fig. 1. Quantitative ratio of different types of hyperproliferative processes of the endometrium

\section{MATERIALS AND METHODS}

We examined 90 patients of the gynecological department of Ternopil Municipal City Hospital №2, who sought medical care during 2017-2019 for hyperplastic processes of the endometrium in reproductive age. The age of women ranged from 18 to 49 years (average $34.52 \pm 2.51$ ).

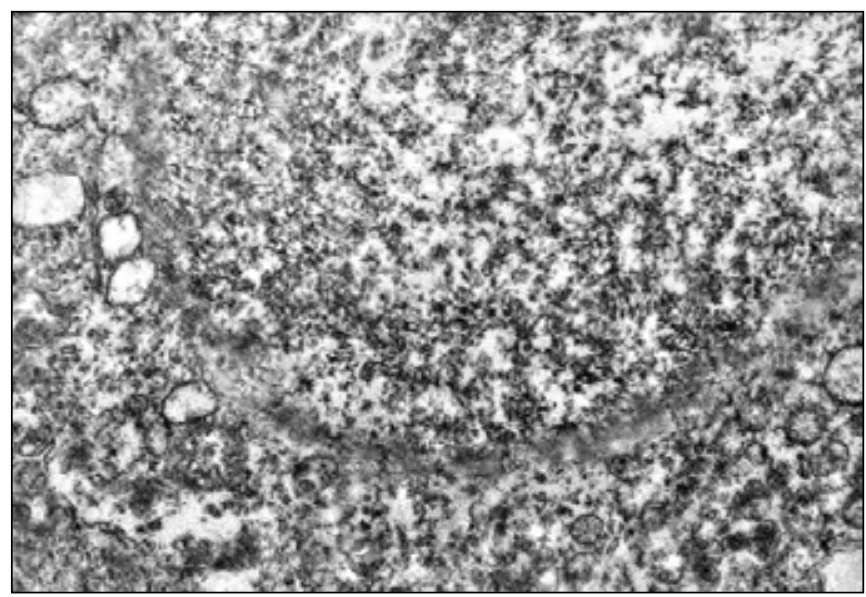

Fig. 2. The structure of the endometrium at the relative norm. Hematoxylin and eosin staining. $\mathrm{x} 200$.

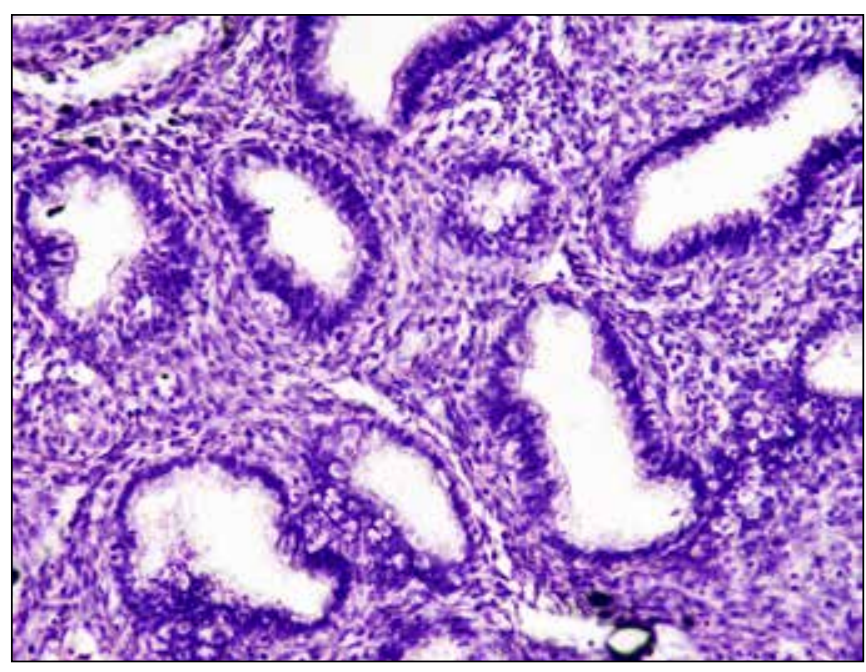

Fig. 4. Complex endometrial hyperplasia without atypia. Focal cytoplasmic vacuolation of endometrial cells. Hematoxylin and eosin staining. $x 400$.
The criteria for inclusion of patients (group I) in the experiment was histologically confirmed the diagnosis of endometrial hyperplastic process (with simple and complex atypical and atypical endometrial hyperplasia according to the classification of WHO endometrial pathology (2014)) [29]. Control - II group consisted of 30 patients

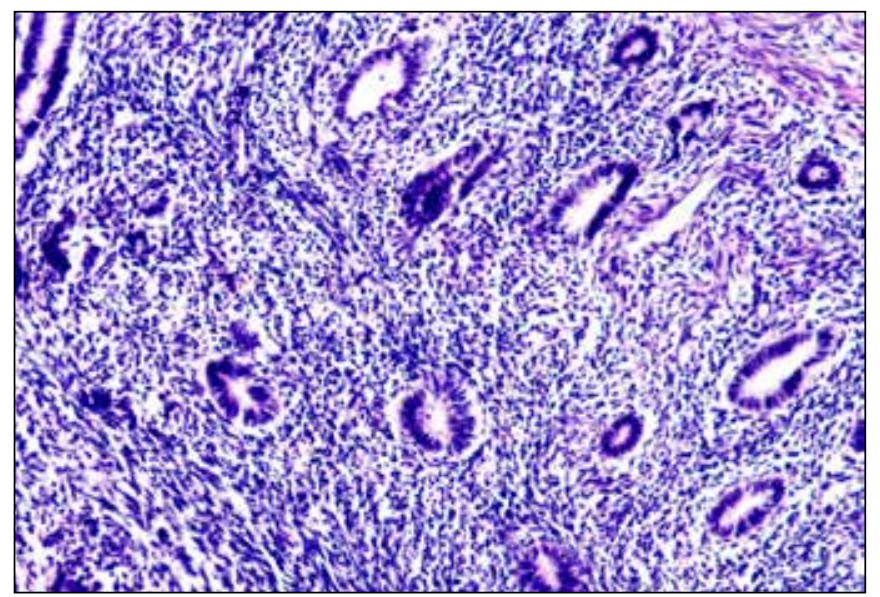

Fig. 3. Simple endometrial hyperplasia without atypia. Cytoplasmic vacuolation of glandular epithelium. Hematoxylin and eosin staining. x 400 .

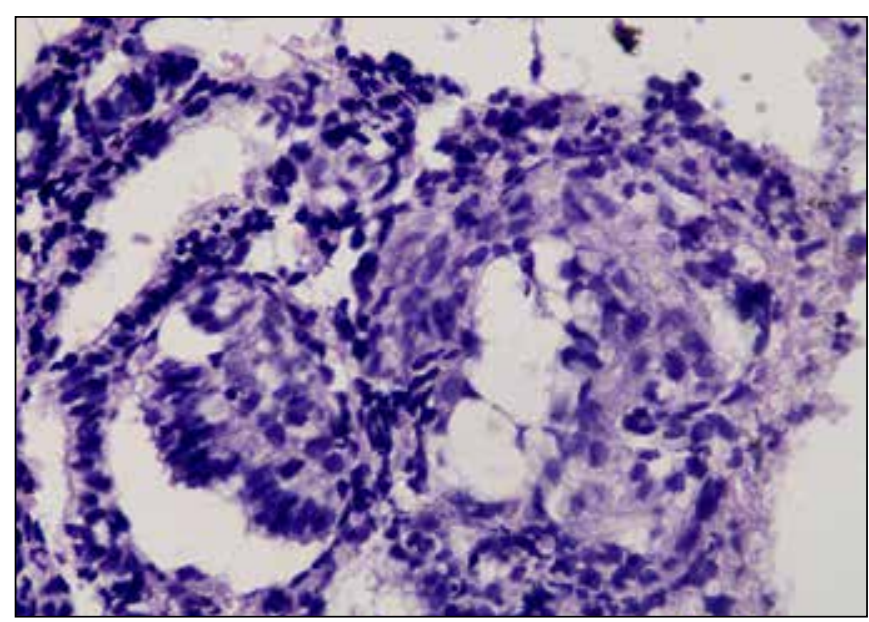

Fig. 5. Complex endometrial hyperplasia without epithelial atypia. Cytoplasmic vacuolation of endometrial cells. Hematoxylin and eosin staining. $\times 200$ 


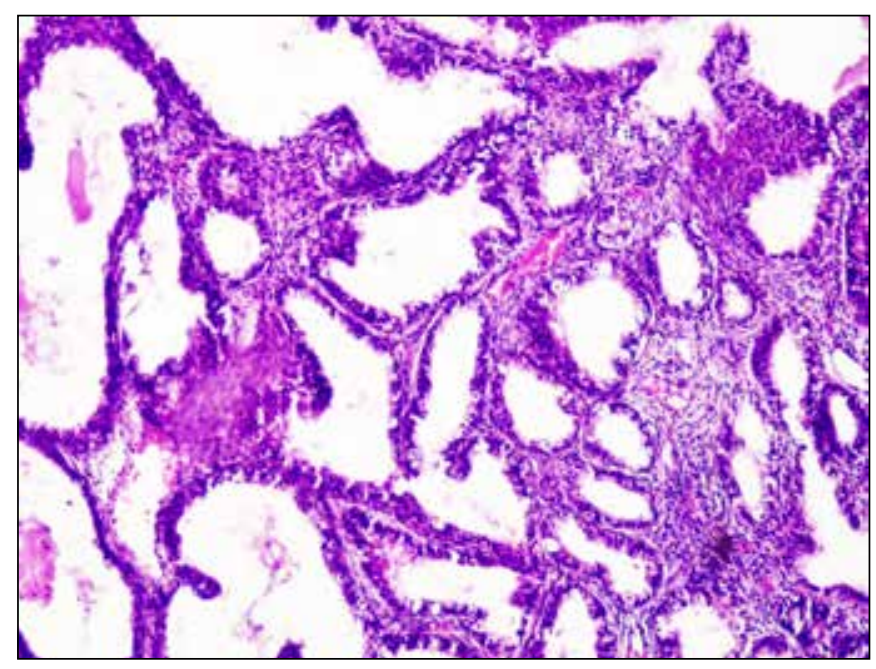

Fig. 6. Complex endometrial hyperplasia with cellular atypia. Cytoplasmic vacuolation of individual epithelial cells. Hematoxylin and eosin staining. $x 400$.

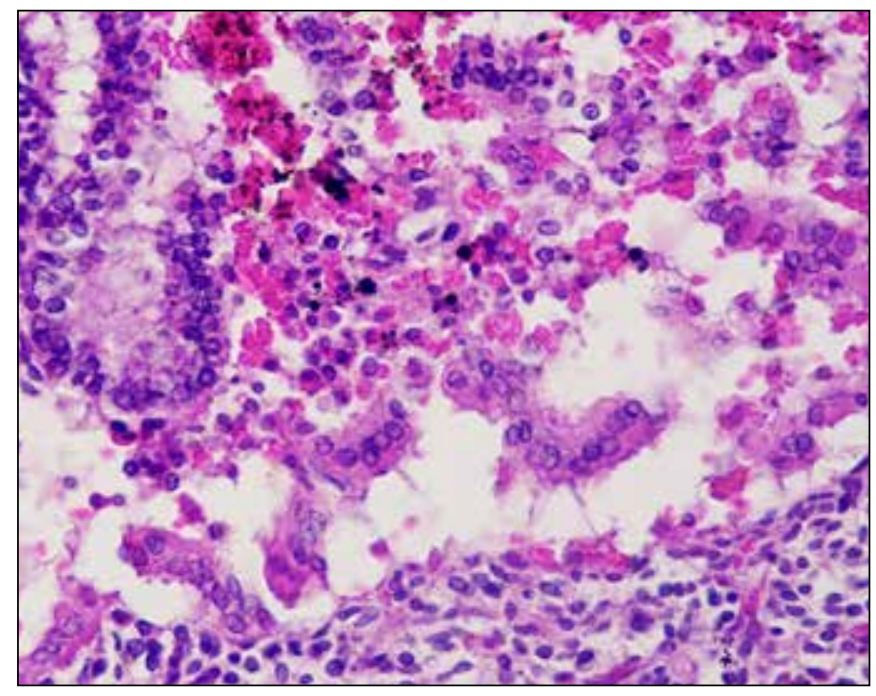

Fig. 8. Cytoplasmic vacuolation of endometrial cells. Focal squamous cell metaplasia is a large foam cell among the endometrial glands. Hematoxylin and eosin staining. $\times 400$.

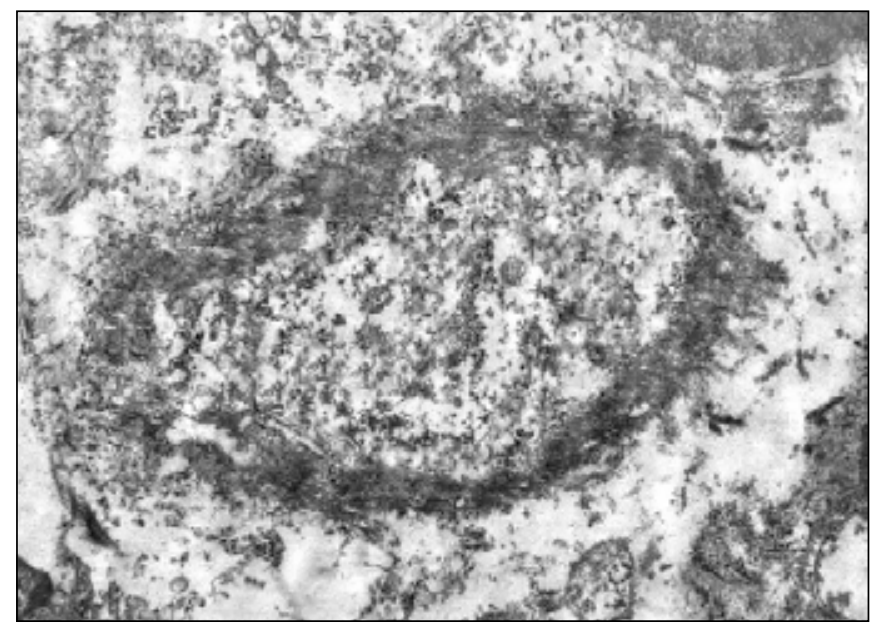

Fig. 10. Fibrillary nucleus (bottom left) and perinuclear cytoplasmic virions about $50 \mathrm{~nm}$ in diameter.

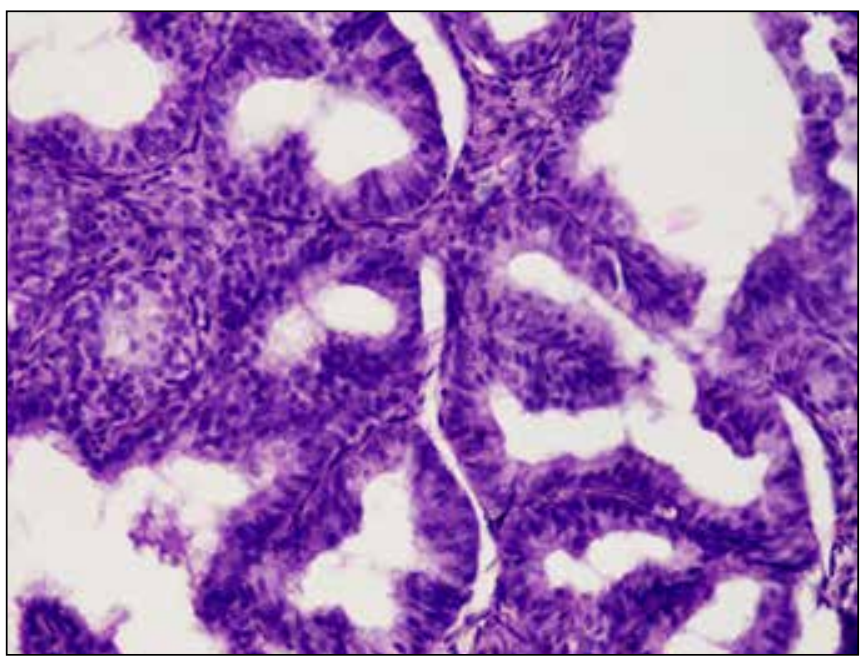

Fig. 7. Complex endometrial hyperplasia without cellular atypia. Cytoplasmic vacuolation of individual epithelial cells. Hematoxylin and eosin staining. $x 400$.

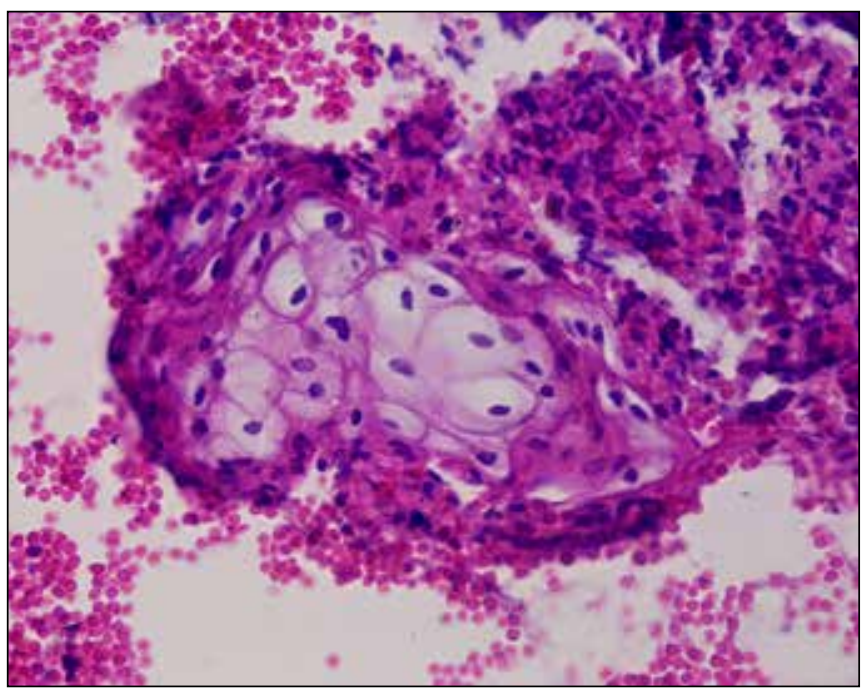

Fig. 9. Fibrillaryl granular nucleus with peripheral displacement of chromatin. Perinuclear nucleocapsids showing a palisading «rosary bead» formation.

of the same age category, healthy patients - volunteers, confirmed by aspiration "Pipelle" (Pipelle de Cornier) endometrial biopsy, followed by histological examination of the evacuated material.

The exclusion criteria were medical records of women with alimentary-constitutional obesity (BMI $>30.0)$, the presence of severe somatic or mental pathology in patients.

Hysteroscopy was performed in the operating room under intravenous anesthesia on hard fiber optics company "KARLSTORZ" from the 6th to the 11th day of the menstrual cycle (with a preserved menstrual cycle). After complete removal of pathologically altered endometrial tissue, its histological examination was performed. The material was fixed in a buffered $10 \%$ formalin solution.

Pipelle biopsy was performed on days 19-23 MC using an aspiration probe. The aspiration probe was inserted into the uterine cavity in an assembled form to the bottom area 
and the contents were aspirated with a piston, resulting in the effect of "suction" to the walls of the uterine cavity and through the existing perforation material which enters the probe. After performing 2-3 aspirations, the conductor was removed and the probe was removed from the uterine cavity. The resulting material is placed in a vial with a $10 \%$ solution of neutral formalin.

Histological examination of endometrial tissue was performed according to the generally accepted method [30] on the basis of the Department of Morphology of the Interdepartmental Training and research laboratory of I. Ya. Horbachevsky Ternopil National Medical University.

The surgical material and endometrial tissue obtained by hysteroscopy and aspiration biopsy of the endometrium were subjected to morphological examination. Biopsy material was fixed in $10 \%$ neutral formalin. Further processing was performed according to the standard generally accepted unified method [30, 31]. Examination of histological specimens was performed using a Nikon Eclipse light microscope (Ci-E) using a digital video camera according to the software manufacturer's recommendations.

For electron microscopic examinations, pieces of endometrium were removed, fixed in $2.5 \%$ glutaraldehyde solution, and postfixed with $1 \%$ osmium tetraoxide solution on phosphate buffer. Further processing was performed according to the generally accepted method [30]. Ultrathin sections made on an ultramicrotome UMPT-7 were contrasted with uranyl acetate, lead citrate according to the Reynolds method and studied under an electron microscope PEM-125K.

For detailed analysis and photo documentation, the image from the microscope was transferred to a computer monitor using a VISION Color CCD Camera and InterVideoWinDUR.

All diagnostic and therapeutic manipulations were performed after the written consent of the patients for examination and treatment in accordance with the protocol approved by the Bioethics Committee (№53 / 03.06.2019). Consent to surgical treatment was obtained before treatment.

The obtained data were processed using standard statistical methods using a personal computer HP PREMIER EXPERIENCE with MicrosoftWord 2010, the graphics were built using Microsoft Excel. Statistical processing was performed by the program Statistics 10 .

\section{RESULTS}

Hyperplastic processes of the endometrium (HPE) are manifestations of pathological proliferation of endometrial glands, which are manifested by a spectrum of atypical morphological, architectural and cytological disorders that lead to an increase in the glandular-stromal ratio in the endometrium.

By means of morphological research of an endometrium features of various types of HPE were revealed (Figure 1).

Group II patients were diagnosed with endometrial structure, which corresponded to the relative norm
(Figure 2). No changes in the inherent hyperproliferative processes of the endometrium in the control group were detected.

At simple atypical HPE (Figure 3) the mucous membrane of a body of a uterus was characterized by numerous glands (increase in number) of various form and size which were unevenly distributed, including cystic-expanded, on separate sites with weakly expressed folds in the direction of a gleam of glands. The structure of the glandular epithelium differed little from the epithelium of the endometrial glands in the proliferation stage, but a significant amount of cytogenic stroma with liquid lymphocytic infiltration (a sign of inflammation of the uterine mucosa) was determined. Dilated capillaries and venules were observed in the superficial parts of individual areas of the endometrium. Simple endometrial hyperplasia without atypia, also known as cystic or mild dysplasia, contained glands of various sizes and shapes that were partially cystically enlarged. There was a moderate ratio of glands / stroma - slightly more than 1 . The nature of epithelial growth and its cytological features are similar to those in the phase of endometrial proliferation, although the number of mitoses is minimal.

In simple atypical HE, the endometrium is similar to simple HE without atypia, but there are signs of atypia of the glandular epithelium in the form of loss of cellular polarity and the presence of vesicular nuclei with pronounced nucleoli. The glandular epithelium is rounded with lost normal perpendicular orientation to the basement membrane.

Structural and functional features of the epithelium in simple and complex atypical HPE (Figure 4,5,7,8) may be morphologically similar, but differs in glands, namely their configuration. Complex HE without atypia was characterized by an increase in the number and size of endometrial glands, their close location and branching. Histostructure - atypia in the form of a significant reduction of the stromal component and extremely complex, complex configuration of the glands. The glands increase in number, usually located "back to back", the minimum number of dividing stroma (in some cases, the stroma is reduced to thin strips of elongated cells), and the figures of mitosis are numerous. The glands have a bizarre, branched shape (complex architecture), but the invasion of the epithelium into the underlying stroma is absent, the glands are clearly separated from each other. The lumen of a number of glands is narrowed, irregularly shaped. In some cases, there are multinuclear papillary structures such as "gland in gland". However, the glands do not merge and the epithelial cells are cytologically normal.

In patients with atypical HPE (adenomatosis) (Figure 6), the endometrium has a more pronounced structural rearrangement of the glandular component compared to simple HPE: branched glands predominate with folds, which is directed into the lumen of the gland against the background of numerous compact glands. Multilayered glandular epithelium with different mitotic activity is 
also fixed. The stroma contains a significant number of fibroblasts, moderate infiltration of lymphocytes, and in some areas there is swelling. In the superficial layers of the endometrium, the glands have dilated lumens with the effects of stasis, fibrin clots are visualized in the blood vessels.

At atypical HPE the endometrium is characterized by excessive growth of a glandular component and its dominance over a stroma, compact arrangement of glands, atypia of cells of glandular epithelium and change of their tectorial properties. In some glands there is a tendency to form "epithelial membranes". There is a hyperchromatosis of nuclei, the nuclear-cytoplasmic index increases. The glandular epithelium retains a multilayered structure with a basement membrane. The epithelial lining of the glands has an uneven inner contour, stratified with loss of polarity. Mitotic activity of cells is variable, pathological mitoses are observed. Blood vessels are mostly thin-walled, there are fibrin clots. Complex HE with atypia has great morphological similarity with highly differentiated endometria adenocarcinoma. Rounded vesicular nuclei with well-defined nucleoli are determined.

Simple atypical glandular HE differs from simple and complex atypical hyperplasia by the presence of atypia of gland cells, which is manifested by a loss of polarity of the location and an unusual configuration of the nuclei, which often acquire a rounded shape. The nuclei of cells in this type of hyperplasia are polymorphic, and large nucleoli are often isolated in them. Complex atypical $\mathrm{HE}$ is characterized by pronounced proliferation of the epithelial component, which is combined with tissue and cell atypia without invasion of the basement membrane of glandular structures. The glands usually lose their regularity for the normal endometrium, they are extremely diverse in shape and size. The epithelium lining the gland consists of large cells with polymorphic, rounded or elongated nuclei with broken polarity and a lot of order of their location.

Histological examination of various types of endometrial hyperplasia in $74.5 \%$ of group I $(\mathrm{p}<0.05)$ revealed a squamous cell component (signs of metaplasia) (Fig. 3, 6). Due to the fact that cytoplasmic vacuolation of the epithelium is often characteristic of koilocytes, which are formed under the influence of the virus in the ectocervical epithelium, we studied various manifestations of endometrial hyperplasia and tried to establish the presence of viral elements in patients with various types of hyperplasia.

Ultrastructural examination of epithelial koilocyte cells of the endometrial glands showed signs of viral infection. Nuclear inclusions consisted of fibrous and granular material, the thickness of the fibrils did not exceed $10 \mathrm{~nm}$ and there was a peripheral displacement of nuclear chromatin. Intranuclear viral particles were not identified, but many cells contained electron-dense perinuclear aggregates, not bound by a membrane, up to $55 \mathrm{~nm}$ in diameter (Figure $9,10)$. Of course, such structural manifestations are not sufficient for accurate verification of the process, but are very characteristic of virus-infected cells.

\section{DISCUSSION}

According to the scientific literature $[2,23,26,32]$ metaplastic processes are most often manifested in the altered endometrium, including hyperplasia, endometritis, atypical hyperplasia or combined pathology. Papillary syncytial metaplasia is an exophytic proliferation of eosinophilic cells that form small syncytia or micropapillary processes on the surface of the endometrium or inside the glands and is often associated with glandular and stromal disorders. Eosinophilic and ciliated cell metaplasias are characterized by epithelial cells with a saturated dense eosinophilic cytoplasm or numerous cilia on the surface. Mucinous metaplasia reflects the presence of a pale, basophilic cytoplasm that is either vacuolated or granular. Squamous cell metaplasia consists of a significant mass of polygonal cells with dense eosinophilic cytoplasm and signs of keratinization. Secretory metaplasia is characterized by the presence of cells that contain sub- or supranuclear vacuoles resembling the early secretory endometrium.

The source of squamous epithelium in endometrial hyperplasia is unclear, but cells are likely to arise as a result of metaplasia or through squamous differentiation of total stem cells or glandular cells and may be stimulated by estrogen [33, 34, 35, 36].

The defeat of epithelial cells by the virus in endometrial hyperplasia is possible in two ways - direct spread from the cervix, or infection through the blood.

Viruses are known to promote the development of tumors in both humans and animals, and HVI, for example, is known to frequently infect the ectocervical epithelium and is closely associated with the development of cervical cancer [23]. It became known that the virus is involved in the pathogenesis of endometrial hyperplasia [25]. It is likely that it exists in epitheliocytes not only as a "passenger", but also as an etiological factor. In our studies, we observed a predominance of squamous cell metaplasia of the glandular epithelium from 39 to $61 \%$ of the studied cases. It became known that it was in complex hyperplasia with atypia that the percentage reached the highest level, which is a precancerous condition (Fig. 2 ). In the control - II group there were no typical cells that could indicate a viral infection of the endometrium.

\section{CONCLUSIONS}

1. Typical morphological change of the endometrium multinucleation, multinuclearity and koilocytotic atypia in women of childbearing age with HPE - was revealed.

2. The presence of infectious pathogens in the endometrium of patients with HPE can be regarded as one of the possible triggers for the development of hyperplastic processes.

Detection of morphological signs of viral lesions in hyperplasia of the endometrium indicates the need for additional research to identify ways of nuclear damage to the endometrium and justifies the search and study of other effects on the endometrium to improve comprehensive drug therapy in patients with HPE. 


\section{REFERENCES}

1. Akrish S., Eskander-Hashoul L., Rachmiel A., Ben-Izhak 0. Clinicopathologic analysis of verrucous hyperplasia, verrucous carcinoma and squamous cell carcinoma as part of the clinicopathologic spectrum of oral proliferative verrucous leukoplakia: A literature review and analysis. Pathol. Res. Pract. 2019;215(12):152670. https://doi.org/ doi:10.1016/j.prp.2019.152670.

2. Farhane F.Z., AlamiZ., Bouhafa T. et al. Primary squamous cell carcinoma of endometrium: case report and literature review. Pan Afr. Med. J., 2018;4 (30):8. https://doi.org/doi:10.11604/pamj.2018.30.8.8983.

3. Boichuk A.V., Shadrina V.S., Vereshchahina T.V. Hyperplasia of endometrium - a modern system-pathogenetic view on the problem (literature review): (literature review). Actual problems of pediatrics, obstetrics and gynecology, 2019;(1):67-72. https://doi. org/10.11603/24116-4944.2019.1.9906.

4. Upadhyaya J.D., Fitzpatrick S.G., Islam M.N., et al. A retrospective 20year analysis of proliferative verrucous leukoplakia and its progression to malignancy and association with high-risk human papillomavirus. Head. Neck.Pathol., 2018;12(4):500-510. https://doi.org/doi:10.1007/ s12105-018-0893-7

5. Li P., Ma J., Zhang X. Et al. Cervical small cell carcinoma frequently presented in multiple high risk HPV infection and often associated with other type of epithelial tumors. Diagn. Pathol., 2018;13(1):31. https:// doi.org/doi:10.1186/s13000-018-0709-9.

6. Cicinelli E., Matteo M., Trojano G. et al. Chronic endometritis in patients with unexplained infertility: Prevalence and effects of antibiotic treatment on spontaneous conception. Reprod. Immunol., 2018;79(1):e12782. https://doi.org/10.1111/aji.12782.

7. Younes J.A., Lievens E., Hummelen R., et al. Women and their microbes: The unexpected friendship. Trends Microbiol., 2018,26(1)16-32. https:// doi.org/10.1016/j.tim.2017.07.008.

8. Vovk I.B., Horban N.Y., Lysiana T.A. et al. The role of the inflammatory factor in the genesis of hyperplastic changes of endometrium in women of reproductive age. Actual Prob. Pediatr., Obstet. Gynecol., 2019;(1):7380. https://doi.org/10.11603/24116-4944.2019.1.10180.

9. Gorban N.Y., Vovk I.B., Hoida N.H., Linchak O.V. Menstrual dysfunction: the situation in the world and in ukraine - in women of reproductive age and with atypical hyperproliferative pathology of the endometrium. Bull. Soc. Hygiene Health Protect. Organiz. Ukraine, 2019;(3): 77-83. https:// doi.org/10.11603/1681-2786.2019.3.10596.

10. Zhao Y.H., Bai Y.P., Mao M.L. et al. Clinicopathological characteristics of HPV $(+)$ oropharyngeal squamous cell carcinoma. Zhonghua bing li xue za zhi, 2019;48(2):127-131. https://doi.org/doi:10.3760/cma.j.is sn.0529-5807.2019.02.010.

11. Du J., Liao X. Superficial spreading squamous cell carcinoma in situ of the cervix involving the endometrium: a rare case presentation and review of literature. Int. J. Clin. Exp. Pathol., 2019;12(11):4162-4166.

12. Dobrokhotova Yu.E., Yakubova K.K. Microbiota of the reproductive tract and hyperplastic processes of the endometrium (literature review). RMJ "Medical Review", Gynecology, 2018;10:14-16.

13. Gorban N.Y., Zadorozhna T.D., Vovk I.B., Zhulkevych I.V. Morphological features of uterine polyps in females of reproductive age. Bull. Sci. Res., 2019;(2):47-52. https://doi.org/10.11603/2415-8798.2019.2.10267

14. Chornenka G.M., Logach M.V. Morphological features of endometrium in women of reproductive age: analysis of morphometric indicators. Achievements of Clinical and Experimental Medicine, 2018;(3):146-150. https://doi.org/10.11603/1811-2471.2018. v0.i3.9275.
15. Adamane S.A., Mittal N., Teni T., et al. Human papillomavirusrelated multiphenotypic sinonasal carcinoma with unique HPV type 52 association: A case report with review of literature. Head Neck Pathol., 2019;13(3):331-338. https://doi.org/doi:10.1007/s12105-018-0969-4.

16. TingthanatikulY., Lertvikool S., Rodratn N., et al. The effects of dienogest on macrophage and natural killer cells in adenomyosis: A randomized controlled study. Int. J. Fertil. Steril., 2018;11(4):279-286. https://doi. org/10.22074/ijfs.2018.5137.

17. Lacheta J. Uterine adenomyosis: Pathogenesis, diagnostics, symptomatology and treatment. Ceska gynekologie, 2019;84(3):240246.

18. Gordts S., Grimbizis G.F., Campo R. Symptoms and classification of uterine adenomyosis, including the place of hysteroscopy in diagnosis. Fertil. Steril., 2018;109(3):380-388. https://doi.org/10.1016/j. fertnstert.2018.01.006

19. Choi E.J., Cho S.B., Lee S.R. et al. Chung, H. Comorbidity of gynecological and non-gynecological diseases with adenomyosis and endometriosis. Obstet. Gynecol. Sci., 2017;60(6):579-586. https://doi.org/10.5468/ ogs.2017.60.6.579.

20. Yang F., Li H., Qi X., Bian C. Post-hysterectomy rare collision vulva tumor with long-term human papilloma virus infection composed of squamous cell carcinoma of the labia major and adenosquamous carcinoma of bartholin gland: A case report. Medicine (Baltimore), 2019;98(39):e17043. https://doi.org/doi:10.1097/ MD.0000000000017043.

21. Thompson A.B., Flowers L.C. Human papillomavirus (HPV). In: Hussen $S$. (eds). Sexually transmitted infections in adolescence and young adulthood. Springer, Cham, 2020:279-297. https://doi. org/10.1007/978-3-030-20491-4_18.

22. Zhulkevych I.V., Kryvokulskyi B.D. Personalization in oncology: individual approach to the prevention of thromboembolic complications during hysterectomy. Bulletin of Social Hygiene and Health Protection Organization of Ukraine, 2018;4:11-18. https://doi.org/10.11603/16812786.2018.4.9875.

23. Wu Q., Chu Z., Han H. et al. Primary squamous cell carcinoma of the endometrium in a woman of reproductive age: a rare case report. J. Int. Med. Res., 2018;46(8):3417-3421. https://doi.org/ doi:10.1177/0300060518776579.

24. Yuksel S., Bektas S., Salman S. Adenoid basal carcinoma combined with invasive squamous cell carcinoma of uterine cervix: A case report of a 37-year-old woman and literature review. Diagn. Cytopathol., 2019;47(10):1051-1054. https://doi.org/doi:10.1002/dc.24258.

25. Rintala M., Vahlberg T., Salo T. et al. Proliferative verrucous leukoplakia and its tumor markers: Systematic review and meta-analysis. Head Neck., 2019;41(5):1499-1507. https://doi.org/doi:10.1002/hed.25569.

26. Tetikkurt S., Çelik E., Taş H. et al. Coexistence of adenomyosis, adenocarcinoma, endometrial and myometrial lesions in resected uterine specimens. Mol. Clin. Oncol., 2018;9(2):231-237. https://doi. org/doi:10.3892/mc0.2018.1660.

27. Vargas M.V., Huang K., NorwitzE. et al. Endometriosis and adenomyosis. Evidence-based Obstetrics and Gynecology. John Wiley \& Sons, Ltd, 2019:8:75-87. https://doi.org/10.1002/9781119072980.ch8.

28. Baker J.M., Chase D.M., Herbst-Kralovetz M.M. Uterine Microbiota: Residents, Tourists, or Invaders? Front. Immunol., 2018;9:208. https:// doi.org/doi:10.3389/fimmu.2018.00208.

29. Kurman R.J., Carcangiu M.L., Herrington C.S. World Health Organisation. Classification of tumours of the female reproductive organs. 4th Revised ed. International Agency for Research on Cancer, 2014. 
30. Bagriy M.M., Dibrova V.A., Popadynets 0.G.; Grishchuk, I.M.; Methods of morphological research: monograph. edited by M.M. Bagriya, V.A. Dibrovy Vinnytsia: New book, 2016:238 p.

31. Nikitina I. et al. Estimation to effigiency of the multifunction metod of endometriosis ovaries treatment. Wiad Lek. 2020;5:868-873.

32. Gorban N., Vovk I., Nikitina I. et al. Immunoglobulin indicators to viruses cytomegal and genital herpes in the blood serum of women with non-atiptcal endometrial hyperproliferative patology. Wiad Lek. 2020;8:1600-1605.

33. Kulavsky V.A., Pushkarev B.A., Kulavsky E.V. et al. Pathology of the endometrium: (diagnostic and therapeutic aspects). Ufa: Healthcare publishing house of Bashkortostan, 2018, p.328.

34. Moreno I., Cicinelli E., Garcia-Grau I., et al. The diagnosis of chronic endometritis in infertile asymptomatic women: a comparative study of histology, microbial cultures, hysteroscopy, and molecular microbiology. Am. J. Obstet. Gynecol., 2018;218(6):602. https://doi.org/10.1016/j. ajog.2018.02.012.

35. Honcharenko G.Y. The role of steroid receptors in the pathogenesis of adenomyosis in the presence of concomitant endometrial pathology in postmenopause. Reports of morphology, 2019;1(25):45-54. https://doi. org/10.31393/morphology-journal-2019-25(1)-07

36. Horban N.Ye., Vovk I.B., Lysiana T.0. et al. Peculiarities of uterine cavity biocenosis in patients with different types of Endometrial Hyperproliferative Pathology. J. Med. Life, 2019;12(3):266-270. https:// doi.org/doi:10.25122/jml-2019-0074.

The work is carried out within the framework of the research work "Optimization of diagnosis and prevention of diseases of the reproductive system and development of pathogenically grounded methods for their correction" (state registration number 011U001801).

\section{ORCID and contributionship:}

Tetiana V. Vereshchahina: 0000-0003-4629-0771 A,E,F

Alla V. Boychuk: 0000-0002-2191-0383 ${ }^{\text {B,C,D }}$

Yuliia B. Yakymchuk: 0000-0002-3905-1310 ${ }^{B, C}$

Iryna M. Nikitina: 0000-0001-6595-2502 D,E,F

Tetiana V. Datsko: 0000-0001-9283-2629 C,E

\section{Conflict of interest:}

The Authors declare no conflict of interest

\section{CORRESPONDING AUTHOR Iryna M. Nikitina}

Sumy State University

12 Rymskoho-Korsakova St.,40030 Sumy, Ukraine

tel: +380662947360

e-mail:nikitina1med@gmail.com

Received: 27.10 .2020

Accepted: 22.02 .2021

A - Work concept and design, B - Data collection and analysis, C - Responsibility for statistical analysis, D-Writing the article, $\mathbf{E}$ - Critical review, $\mathbf{F}$ - Final approval of the article 